\title{
Exercise habituation is effective for improvement of periodontal disease status: a prospective intervention study
}

This article was published in the following Dove Press journal:

Therapeutics and Clinical Risk Management

\author{
Shoei Omori, ${ }^{1,2}$ Fumihiko \\ Uchida, ${ }^{3}$ Sechang Oh, ${ }^{4,5}$ Rina \\ So, ${ }^{6}$ Takehiko Tsujimoto, ${ }^{7}$ \\ Toru Yanagawa, ${ }^{8}$ Satoshi \\ Sakai, ${ }^{4}$ Junichi Shoda, ${ }^{4,5}$ Kiyoji \\ Tanaka, ${ }^{9}$ Hiroki Bukawa ${ }^{8}$ \\ 'Oral and Maxillofacial Surgery, \\ Clinical Sciences, Graduate School \\ of Comprehensive Human Sciences, \\ University of Tsukuba, Tsukuba, Ibaraki, \\ Japan; ${ }^{2}$ Department of Dental Oral \\ Surgery, Kitaibaraki City Hospital, \\ Kitaibaraki, lbaraki, Japan; ${ }^{3}$ Department \\ of Oral and Maxillofacial Surgery, \\ University of Tsukuba Hospital, \\ Tsukuba, Ibaraki, Japan; ${ }^{4}$ Department \\ of Medical Sciences, Faculty of \\ Medicine, University of Tsukuba, \\ Tsukuba, Ibaraki, Japan; ${ }^{5}$ The Center of \\ Sports Medicine and Health Sciences, \\ Tsukuba University Hospital, Tsukuba, \\ Ibaraki, Japan; ${ }^{6}$ Research Center \\ for Overwork-Related Disorders, \\ National Institute of Occupational \\ Safety and Health, Kawasaki, \\ Kanagawa, Japan; ${ }^{7}$ Department of \\ Sports Medicine, Faculty of Human \\ Sciences, Shimane University, Matsue, \\ Shimane, Japan; ${ }^{8}$ Department of Oral \\ and Maxillofacial Surgery, Faculty \\ of Medicine, University of Tsukuba, \\ Tsukuba, Ibaraki, Japan; ${ }^{\circ}$ Department \\ of Sports Medicine, Faculty of Health \\ and Sport Sciences, University of \\ Tsukuba, Tsukuba, Ibaraki, Japan
}

Correspondence: Fumihiko Uchida Department of Oral and Maxillofacial Surgery, University of Tsukuba Hospital, I-I-I Tennodai, Tsukuba, Ibaraki 305-8575, Japan

Tel +8I 298533052

Fax +8I 298533052

Email uchiyamadaI03I@yahoo.co.jp
Background and purpose: Periodontal disease is closely related to lifestyle-related diseases and obesity. It is widely known that moderate exercise habits lead to improvement in lifestylerelated diseases and obesity. However, little research has been undertaken into how exercise habits affect periodontal disease. The purpose of this study was to examine the effect of exercise habits on periodontal diseases and metabolic pathology.

Methods: We conducted a prospective intervention research for 12 weeks. The subjects were 71 obese men who participated in an exercise and/or dietary intervention program. Fifty subjects were assigned to exercise interventions (exercise intervention group) and 21 subjects were assigned to dietary interventions (dietary intervention group). This research was conducted before and after each intervention program.

Results: In the exercise intervention group, the number of teeth with a probing pocket depth (PPD) $\geq 4$ mm significantly decreased from $14.4 \%$ to $5.6 \%(P<0.001)$, and the number of teeth with bleeding on probing (BOP) significantly decreased from $39.8 \%$ to $14.4 \%(P<0.001)$. The copy counts of Tannerella forsythia and Treponema denticola decreased significantly $(P=0.001)$. A positive correlation was found between the change in the copy count of $T$. denticola and the number of teeth with PPD $\geq 4 \mathrm{~mm}(P=0.003)$ and the number of teeth with BOP $(P=0.010)$. A positive correlation was also found between the change in the copy count of $T$. denticola and body weight $(P=0.008)$, low-density lipoprotein cholesterol $(P=0.049)$, and fasting insulin $(P=0.041)$. However, in the dietary intervention group the copy count of $T$. denticola decreased significantly $(P=0.007)$ and there was no correlation between the number of periodontal diseasecausing bacteria and PPD and BOP.

Conclusion: Our results are the first to show that exercise might contribute to improvements in periodontal disease.

Keywords: bacteria, intervention studies, lifestyle, metabolic syndrome, obesity, periodontal disease, periodontal status

\section{Introduction}

Periodontal disease and dental caries are the two major diseases treated by dentists. It has been reported that there is a relationship between periodontal disease and systemic diseases. ${ }^{1}$ Periodontal diseases are bacterial infections occurring in the periodontal tissues and are considered to be lifestyle-related diseases. Periodontal disease is clinically diagnosed by examination with a dental probe. If the probing pocket depth (PPD) is $\geq 4 \mathrm{~mm}$, it is diagnosed as moderate periodontitis. If there is bleeding on probing (BOP), it is diagnosed as gingivitis. 
The most well-known periodontal disease-causing bacteria are three bacterial species of the red complex: Porphyromonas gingivalis, Tannerella forsythia, and Treponema denticola. ${ }^{2}$ These three bacterial species are said to be the most highly pathogenic microorganisms, and their frequency increases as the periodontal pocket gets deeper. It has been reported that periodontal disease and systemic diseases, such as diabetes, cardiovascular disease, and aspiration pneumonitis, are closely related. In recent years, a relationship between periodontal disease and nonalcoholic fatty liver disease, which is a lifestyle-related disease, has been reported. ${ }^{3}$

Periodontal diseases are closely related to lifestyle and obesity. Moderate exercise habits contribute to improvement in lifestyle-related diseases and obesity. A pathology that combines a lifestyle-related disease and obesity is called metabolic syndrome. Metabolic syndrome is identified by symptoms including abdominal obesity, dyslipidemia, hyperglycemia, and hypertension. One report suggested that metabolic syndrome raises the risk of developing type 2 diabetes by a factor of $5 .{ }^{4}$

Obesity has been implicated as the most biologically relevant risk factor in the relationship between periodontal disease and metabolic syndrome..$^{5}$ Obese people have a higher risk of periodontitis compared with healthy subjects, ${ }^{6,7}$ and a correlation between severe periodontitis and metabolic syndrome has been confirmed in patients aged $\geq 45 .{ }^{8}$ A Japanese study reported that the greater the number of metabolic syndrome diagnostic criteria that apply, the higher the risk of periodontitis. ${ }^{9}$ In a systematic review reported by Chaffee and Weston, ${ }^{10}$ the prevalence of periodontal disease in obese people was 1.35 , compared with 1.00 in healthy subjects, while Suvan et a ${ }^{11}$ reported an odds ratio of 1.81 .

It is also widely known that moderate exercise habits lead to improvement in lifestyle-related diseases. Some reports suggested that moderate exercise routinely alleviates systemic inflammatory reactions ${ }^{12}$ and that a decrease in the amount of physical activity increases the risk of many chronic diseases. ${ }^{13}$ Correlations have also been reported between the presence or absence of physical activity and gingival bleeding and calculus deposition. ${ }^{14}$

Although periodontal disease is closely associated with lifestyle-related diseases and obesity, there has been little research into how exercise habits affect periodontal disease. The purpose of this study was to examine the influence of exercise habits on periodontal disease and metabolic pathology.

\section{Participants and methods}

A recruitment-based, exercise intervention program was run for 12 weeks, three times/week, and clinical tests at baseline and week 12 were carried out at the University of Tsukuba Hospital (Ibaraki, Japan) from August to December 2014.

We recruited participants who were obese (body mass index $>25 \mathrm{~kg} / \mathrm{m}^{2}$ ) adult men through an advertisement in a local newspaper according to the study criteria. We adopted the following eligibility criteria for participation in this study: male aged 31-64 years without exercise habits ( $\leq 1$ session/ week and $\leq 30$ minutes/session) over the past year and serious diseases of oral cavity. The subject requirements were as follows: people who had no routine exercise habits, people who had never undertaken a weight reduction program, people who desired weight reduction, people who wanted to review their exercise habits, and people who understood and agreed with the purpose of our study.

Initially, 67 applicants from Ibaraki prefecture participated. All 67 people were recruited in advance of the exercise intervention program. After the briefing held before the program, six people were excluded: one person declined to participate, three people did not meet the inclusion criteria, and two people had problems related to the electrocardiogram. Of the 61 people who participated in the exercise intervention program, nine people dropped out and were excluded: one person did not receive the allocated intervention, three people had poor physical condition, three people found that they were too busy, one person had depression, and one person had a nonresearch-related disease. Of the 52 people who completed the exercise intervention program, two people were excluded as we were unable to collect saliva because they could not attend the postmeasurement. Thus, 17 people were not included in the study sample, and the analysis of the exercise intervention group was conducted in 50 cases.

All 50 subjects were enrolled in exercise programs composed of resistance training (exercise volume $=170 \sim 190 \mathrm{kcal} /$ session) or aerobic training in cycling session for 20 40 minutes at $60 \%-85 \% \mathrm{VO}_{2 \max }$ (exercise volume $=180-360 \mathrm{kcal} / \mathrm{session}$ ). Details of the strength and frequency of the resistance training were as follows: intensity ( $50 \%-70 \% 1$ repetition maximum, 1-2 minutes rest, total 3 sets); crunches (15 repetitions [reps] per set); and leg extension, leg press, leg curl, chest press, seated row, and lat pull-down (all 12 reps per set). ${ }^{15}$

In addition, we performed a 12-week dietary intervention program to collect data for the reference group from April 2015 to June 2015 at the University of Tsukuba. We adopted the following eligibility criteria for participation in this study. The subject requirements were the following: people who had no routine dietary restrictions, people who had never undertaken a weight reduction program, people who desired weight reduction, people who wanted 
to review their diet habits, and people who understood and agreed with the purpose of our study.

Initial 35 applicants from Ibaraki prefecture participated. All 35 people were recruited in advance of the dietary intervention program. After the briefing held before the program, five people were excluded: two people declined to participate and three people did not meet the inclusion criteria. Of the 30 people who participated in the dietary intervention program, seven people dropped out and were excluded: four people did not receive the allocated intervention and three people found that they were too busy. Of the 23 people who completed the exercise intervention program, two were excluded as we were unable to collect saliva because they could not attend the postmeasurement. Thus, 14 people were not included in the study sample, and the analysis of the dietary intervention group was conducted in 21 cases.

The dietary intervention program provided lectures and consultations on nutrition and dietary habits once a week for 90 minutes, recorded the items taken for each meal, and set a target of $560 \mathrm{kcal}$ per meal and 1,680 kcal per day. The detailed descriptions of dietary restriction session have been published elsewhere. ${ }^{16}$

All the participants were separate cases, and no one participated in both the programs. This prospective research was conducted before and after each intervention program. There is no dental intervention, but it is based on the lifestyle modification research aimed at acquiring good exercise and dietary habits. Fifty subjects were assigned to exercise interventions (exercise intervention group), and 21 subjects were assigned to dietary interventions (dietary intervention group). Premeasurement was carried out 1 month before the program, and postmeasurement was carried out 1 month after the program ended.

Measurement items were modified dental questionnaire survey by Japan Dental Association, medical interview and intraoral examination by a dentist, the number of periodontal disease-causing bacteria in saliva, body composition, and a blood test. Premeasurement and postmeasurement were performed in the same way. Items of the questionnaire survey were toothbrushing time, toothbrushing frequency, the use of toothbrushing aids, the frequency of dental examinations, the presence or absence of toothbrushing at the dental clinic, the presence or absence of drinking, and the presence or absence of smoking. In the medical interview, we enquired about subjective symptoms including gum bleeding, gingival swelling, halitosis, and tooth mobility. The intraoral examination recorded the number of residual teeth, the number of restored teeth, the number of carious teeth, PPD, BOP, tooth movement, and mouth dryness. In addition, we examined the number of teeth with PPD $\geq 4 \mathrm{~mm}$ and the number of teeth with BOP among of the number of residual teeth.

Saliva was collected before and after the program, and the DNA was extracted. Saliva production was stimulated by chewing paraffin gum for 3-5 minutes before sampling by the discharge method. A $200-\mu \mathrm{L}$ sample of saliva was transferred to a microtube, and DNA extraction was carried out by using DNeasy Blood \& Tissue Kit (Qiagen, Venlo, Limburg, the Netherlands). The extracted DNA was stored at $-30^{\circ} \mathrm{C}$ until analysis. Bacterial counts of three red complex species in saliva ( $P$. gingivalis, $T$. forsythia, and $T$. denticola) were examined by qPCR. $P$. gingivalis $\mathrm{RO}-0010, T$. forsythia RO - 0014, and T. denticola RO - 0013 (Techno Suruga Labo Co., Shizuoka, Japan) were used as calibration samples and primers for qPCR. The DNA standard curve consisted of known amounts of molecules of purified PCR products isolated from agarose gels. The DNA concentration was estimated by absorbance at $260 \mathrm{~nm}$, and a series of 10 -fold dilutions was prepared for standard curves as previously described. The amount of bacterial DNA in the samples was estimated from the standard curve. Real-time PCR was performed by using the Bio-Rad iQ5 System (Bio-Rad Laboratories Inc., Hercules, CA, USA). The reaction mixtures contained $2.0 \mu \mathrm{L}$ of purified DNA from saliva samples, $0.2 \mu \mathrm{L}$ of primers, and 5.0 $\mu \mathrm{L}$ iQ SYBR Green Supermix (Bio-Rad Laboratories Inc.). Distilled water was added to a final volume of $10 \mu \mathrm{L}$. All data were analyzed using the iQ5 Optical System Software (Bio-Rad Laboratories Inc.). All experiments for quantifying bacterial levels were performed in triplicate and independently repeated twice.

In addition, body composition tests (eg, body weight, body fat percentage, and abdominal girth) as well as blood sampling tests such as liver function, kidney function, and blood count (Kotobiken Medical Laboratories Inc., Ibaraki, Japan), were carried out.

These study protocols were approved by the institutional review board of the University of Tsukuba. All the procedures were carried out in accordance with the principles of the Declaration of Helsinki. We fully explained the purpose and design of the study to all the participants, and each participant signed an informed consent document. Approval was granted for both the exercise intervention program (no 25-124) and the dietary intervention program (no 26-118).

The data were analyzed using SPSS Version 23.0 for Windows (IBM, Chicago, IL, USA). We used a $\chi^{2}$ test, Wilcoxon signed-rank test, and Pearson's product-moment correlation coefficient with the level of statistical significance set at $P<0.05$. 


\section{Results}

The results of the questionnaire showed that there were no significant differences between the exercise and dietary intervention groups before or after the program (Table 1). The intraoral examinations in the exercise intervention group showed that the number of teeth with PPD $\geq 4 \mathrm{~mm}$ significantly decreased from $14.4 \%$ before the program to $5.6 \%$ after the program $(P<0.001)$ and that the number of teeth with BOP significantly decreased from $39.8 \%$ to $14.4 \%(P<0.001$; Table 2). In the dietary intervention group, there was no significant difference between before and after the program in the number of teeth with PPD $\geq 4 \mathrm{~mm}$ nor in the number of teeth with BOP. The results of qPCR in the exercise intervention group showed that the copy count of $T$. forsythia and $T$. denticola decreased significantly after the program $(P=0.001$; Table 2). In the dietary intervention group, there were significant differences between before and after the program in the copy count of $P$. gingivalis $(P=0.007)$ and $T$. denticola $(P=0.023$; Table 2). There was no significant difference in the number of remaining teeth in either group (Table 2).

There were significant differences between before and after the program in body weight, alanine transaminase (ALT), gamma glutamyl transferase $(\gamma-\mathrm{GT})$, high-density lipoprotein cholesterol, free fatty acids (FFAs), and hemoglobin A1c in the exercise intervention group (Table 3). There were significant differences between before and after the program in body weight, aspartate transaminase (AST), ALT, $\gamma$-GT, T-Cho, low-density lipoprotein cholesterol (LDL-C), FFAs, fasting insulin, and HbA1c in the dietary intervention group (Table 4).
A positive correlation was found between the change in the copy count of $T$. denticola and the number of teeth with $\mathrm{PPD} \geq 4 \mathrm{~mm}(P=0.003)$ and the number of teeth with BOP $(P=0.010$; Figure 1). A positive correlation was also found between the change in the copy count of $T$. denticola and the change in body weight $(P=0.008)$, LDL-C $(P=0.049)$, and fasting insulin ( $P=0.041$; Table 5; Figure 2$)$. In the dietary intervention group, there was no correlation between the copy count of periodontitis bacteria and any of the items (Table 6).

\section{Discussion}

In the present study, the number of teeth with PPD $\geq 4 \mathrm{~mm}$, the number of teeth with BOP, and the copy count of T. denticola decreased significantly after the program in the exercise intervention group. There were positive correlations between the copy count of $T$. denticola and the number of teeth with $\mathrm{PPD} \geq 4 \mathrm{~mm}$, the number of teeth with BOP, body weight, LDL-C level, and fasting insulin level in the exercise intervention group. However, in the dietary intervention group, there were no correlations between the copy count of periodontitis bacteria and any of the items. The results of the questionnaire survey revealed that there were no significant changes in the frequency or duration of toothbrushing or the use of auxiliary instruments after the program. This finding suggests that there was no change in the motivation for improved oral hygiene. Our findings suggest that the exercise intervention improved obesity and metabolic pathology and activated the local immune reaction, thus improving the condition of the periodontium. Interestingly, there was a positive

Table I Results of the questionnaire survey and medical interview pre- to postintervention

\begin{tabular}{|c|c|c|c|}
\hline Variable & Preintervention & Postintervention & $P$-value \\
\hline \multicolumn{4}{|l|}{ Exercise intervention group $(n=50)$} \\
\hline Number of brushings per day (times)* & 2 & 2 & 0.807 \\
\hline Brushing time per day (minutes)* & 6 & 6 & 0.206 \\
\hline Use of auxiliary instrument (floss interdental brush, etc.) (\%)** & 24 & 26 & 0.817 \\
\hline Regular visit to a dental office $(\%)^{* *}$ & 20 & 20 & 1.000 \\
\hline Gingival bleeding during tooth brushing (\%)** & 28 & 24 & 0.648 \\
\hline Teeth stinging $(\%)^{* *}$ & 24 & 36 & 0.190 \\
\hline The gingiva retracted and the tooth became longer (\%)** & 18 & 24 & 0.461 \\
\hline \multicolumn{4}{|l|}{ Dietary intervention group $(n=2 I)$} \\
\hline Number of brushings per day (times)* & 2 & 2 & 0.180 \\
\hline Brushing time per day (minutes)* & 6 & 7 & 0.937 \\
\hline Use of auxiliary instrument (floss interdental brush, etc.) (\%)** & 24 & 29 & 0.726 \\
\hline Regular visit to a dental office $(\%)^{* *}$ & 24 & 24 & 1.000 \\
\hline Gingival bleeding during tooth brushing (\%)** & 29 & 33 & 0.739 \\
\hline Teeth stinging $(\%)^{* *}$ & 24 & 33 & 0.495 \\
\hline The gingiva retracted and the tooth became longer (\%)** & 33 & 33 & 1.000 \\
\hline
\end{tabular}


Table 2 Periodontal disease tests and bacterial quantities, amount of change from pre- to postintervention

\begin{tabular}{|c|c|c|c|c|}
\hline Variable & Preintervention & Postintervention & Change & $P$-value \\
\hline \multicolumn{5}{|l|}{ Exercise intervention group $(n=50)$} \\
\hline Number of remaining teeth & $27.0 \pm 3.9$ & $27.0 \pm 3.9$ & 0 & 0.317 \\
\hline Number of teeth with PPD $\geq 4$ mm (\%) & $14.4 \pm 12.9$ & $5.6 \pm 8.5$ & -8.8 & $<0.00 I^{*}$ \\
\hline Number of BOP positive teeth (\%) & $39.8 \pm 18.0$ & $14.4 \pm 7.7$ & -25.4 & $<0.00 I^{*}$ \\
\hline Porphyromonas gingivalis ( $\times 10^{3}$ copy $/ 5 \mu \mathrm{L}$ saliva) & $11,370.9 \pm 16,961.0$ & $|3,6| 5.8 \pm 2|, 2| 6.9$ & $2,245.0$ & 0.449 \\
\hline Tannerella forsythia $\left(\times 10^{3}\right.$ copy $/ 5 \mu \mathrm{L}$ saliva $)$ & $1,416.4 \pm 2,000.9$ & $747.8 \pm 958.6$ & -668.6 & $0.001 *$ \\
\hline Treponema denticola $\left(\times 10^{3}\right.$ copy $/ 5 \mu \mathrm{L}$ saliva $)$ & $377.4 \pm 521.9$ & $191.7 \pm 533.9$ & -185.7 & $0.001 *$ \\
\hline \multicolumn{5}{|l|}{ Dietary intervention group $(n=2 \mathrm{I})$} \\
\hline Number of remaining teeth & $27.0 \pm 6.1$ & $27.0 \pm 6.1$ & 0 & 0.180 \\
\hline Number of teeth with PPD $\geq 4$ mm (\%) & $12.5 \pm 18.7$ & $9.1 \pm 27.0$ & -3.4 & 0.246 \\
\hline Number of BOP positive teeth (\%) & $39.6 \pm 17.5$ & $48.7 \pm 28.6$ & 9.1 & 0.092 \\
\hline$P$. gingivalis $\left(\times 10^{3}\right.$ copy $/ 5 \mu \mathrm{L}$ saliva $)$ & $20,456.3 \pm 24,326.8$ & $33, \mid 18.2 \pm 47,638.1$ & $|2,66| .9$ & $0.007^{*}$ \\
\hline T. forsythia $\left(\times 10^{3}\right.$ copy $/ 5 \mu \mathrm{L}$ saliva $)$ & $4,933.8 \pm 5,6 \mid 4.6$ & $6,107.8 \pm 1,829.8$ & I,I I 74.0 & 0.357 \\
\hline T. denticola $\left(\times 10^{3}\right.$ copy $/ 5 \mu \mathrm{L}$ saliva $)$ & $500.0 \pm 619.8$ & $294.4 \pm 435.8$ & -205.6 & $0.023^{*}$ \\
\hline
\end{tabular}

Notes: Values are presented as mean $\pm \mathrm{SD}$. Wilcoxon signed-rank test was used for analysis. $* P<0.05$. Abbreviations: BOP, bleeding on probing; PPD, probing pocket depth.

correlation between periodontal disease-causing bacteria and body weight, LDL-C, and fasting insulin, suggesting that the improvement in the periodontal condition may be related to improvement in obesity, hyperlipidemia, and diabetes.

\section{Factors affecting periodontal disease}

Periodontal disease is directly caused by periodontal diseasecausing bacteria, but indirect causes include host factors and environmental factors. These factors are thought to contribute significantly to the onset and progress of periodontal disease pathology. Host factors include age, sex, diabetes, and obesity. ${ }^{17,18}$ Environmental factors include oral cleaning

Table 3 Amount of change in body weight and blood test results from pre- to postintervention

\begin{tabular}{|c|c|c|c|c|}
\hline \multirow[t]{2}{*}{ Variable } & \multicolumn{4}{|c|}{ Exercise intervention group $(n=50)$} \\
\hline & Pre & Post & Change & $P$-value \\
\hline Body weight (kg) & $83.5 \pm 13.6$ & $84.0 \pm 13.6$ & 0.5 & $0.018 *$ \\
\hline AST (U/L) & $27.9 \pm 15.3$ & $28.4 \pm 15.3$ & 0.6 & 0.309 \\
\hline ALT (U/L) & $40.7 \pm 34.1$ & $37.6 \pm 31.4$ & -3.1 & $0.005^{*}$ \\
\hline$\gamma-\mathrm{GT}(\mathrm{U} / \mathrm{L})$ & $54.4 \pm 44.4$ & $50.9 \pm 56.9$ & -3.5 & $0.004^{*}$ \\
\hline T-Cho (mg/dL) & $205.6 \pm 32.6$ & $204.4 \pm 36.5$ & -1.2 & 0.674 \\
\hline HDL-C (mg/dL) & $50.0 \pm I I .1$ & $52.0 \pm 11.6$ & 2.0 & $0.014^{*}$ \\
\hline LDL-C (mg/dL) & $130.0 \pm 28 . \mid$ & $127.7 \pm 30.3$ & -2.3 & 0.505 \\
\hline FFAs (mEq/L) & $0.6 \pm 0.3$ & $0.5 \pm 0.2$ & -0.2 & $<0.00 I^{*}$ \\
\hline $\begin{array}{l}\text { Fasting blood } \\
\text { glucose }(\mathrm{mg} / \mathrm{dL})\end{array}$ & $100.4 \pm 20.4$ & $98.5 \pm 13.0$ & -1.9 & 0.836 \\
\hline Fasting insulin $(\mu \mathrm{U} / \mathrm{mL})$ & $11.8 \pm 8.7$ & $10.7 \pm 6.5$ & -1.1 & 0.248 \\
\hline $\mathrm{HbAlc} \mathrm{( \% )}$ & $5.7 \pm 0.8$ & $5.7 \pm 0.6$ & 0.0 & $0.006^{*}$ \\
\hline
\end{tabular}

Notes: Values are presented as mean \pm SD. Wilcoxon signed-rank test was used for analysis. $* P<0.05$.

Abbreviations: ALT, alanine transaminase; AST, aspartate transaminase alanine; FFAs, free fatty acids; $\gamma$-GT, gamma glutamyl transferase; HbAlc, hemoglobin Alc; HDL-C, high-density lipoprotein cholesterol; LDL-C, low-density lipoprotein cholesterol. conditions, smoking habits, and stress stimulation. ${ }^{19-22}$ Exercise habits may be a new environmental factor or may simply exert an influence on known environmental factors. In this study, subjects in each intervention program completed a survey before and a survey after the program. Therefore, of these factors, age, sex, and smoking habits can be excluded.

The questionnaire results indicated that there was no change in the motivation for oral cleaning conditions; therefore, changes in oral hygiene can also be excluded. The remaining factors affecting periodontal disease are obesity, diabetes, and stress stimulation. In this study, we considered obesity, which is closely related to the content of the program.

Table 4 Amount of change in body weight and blood tests from pre- to postintervention

\begin{tabular}{|c|c|c|c|c|}
\hline \multirow[t]{2}{*}{ Variable } & \multicolumn{4}{|c|}{ Dietary intervention group $(n=2 I)$} \\
\hline & Pre & Post & Change & $P$-value \\
\hline Body weight (kg) & $80.8 \pm 10.3$ & $72.1 \pm 9.6$ & -8.6 & $<0.001^{*}$ \\
\hline AST (U/L) & $26.8 \pm 10.1$ & $20.0 \pm 5.7$ & -6.8 & $0.002^{*}$ \\
\hline ALT (U/L) & $33.2 \pm 23.6$ & $23.6 \pm 10.7$ & -9.6 & $0.026 *$ \\
\hline$\gamma-\mathrm{GT}(\mathrm{U} / \mathrm{L})$ & $41.6 \pm 18.8$ & $24.0 \pm 9.9$ & -17.5 & $<0.00 I^{*}$ \\
\hline T-Cho (mg/dL) & $212.7 \pm 39.0$ & $185.3 \pm 40.4$ & -27.3 & $0.002 *$ \\
\hline HDL-C (mg/dL) & $53.8 \pm 12.7$ & $53.1 \pm 11.7$ & -0.6 & 0.497 \\
\hline LDL-C (mg/dL) & $136.4 \pm 36.2$ & $111.8 \pm 34.8$ & -24.6 & $0.002 *$ \\
\hline FFAs (mEq/L) & $0.5 \pm 0.2$ & $0.6 \pm 0.2$ & 0.1 & $0.047^{*}$ \\
\hline $\begin{array}{l}\text { Fasting blood } \\
\text { glucose (mg/dL) }\end{array}$ & $101.4 \pm 21.0$ & $94.8 \pm 8.3$ & -6.6 & 0.102 \\
\hline Fasting insulin $(\mu \mathrm{U} / \mathrm{mL})$ & II.I \pm 7.3 & $6.5 \pm 2.9$ & -4.6 & $0.002 *$ \\
\hline HbAlc (\%) & $5.7 \pm 0.5$ & $5.3 \pm 0.2$ & -0.2 & $0.003 *$ \\
\hline
\end{tabular}

Notes: Values are presented as mean \pm SD. Wilcoxon signed-rank test was used for analysis. $* P<0.05$.

Abbreviations: ALT, alanine transaminase; AST, aspartate transaminase alanine; FFAs, free fatty acids; $\gamma$-GT, gamma glutamyl transferase; HbAlc, hemoglobin Alc; HDL-C, high-density lipoprotein cholesterol; LDL-C, low-density lipoprotein cholesterol. 


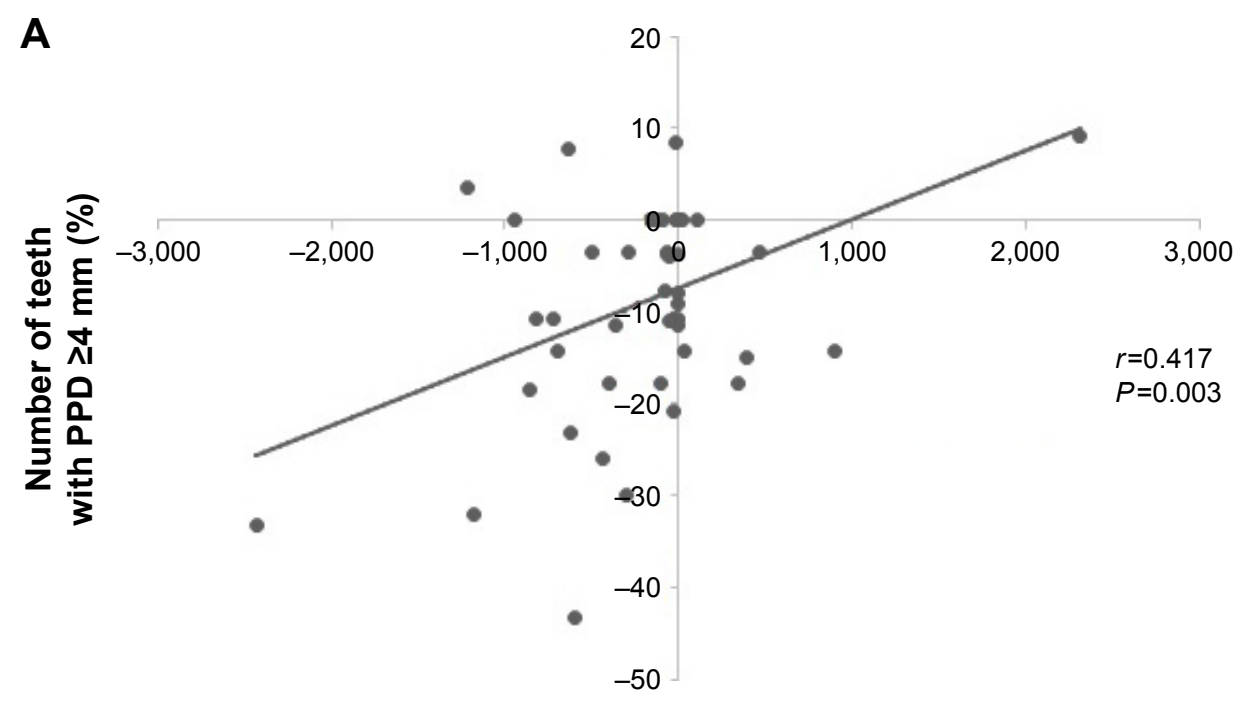

Change in the copy count of $T$. denticola $\left(\times 10^{3}\right.$ copy $/ 5 \mu \mathrm{L}$ saliva)

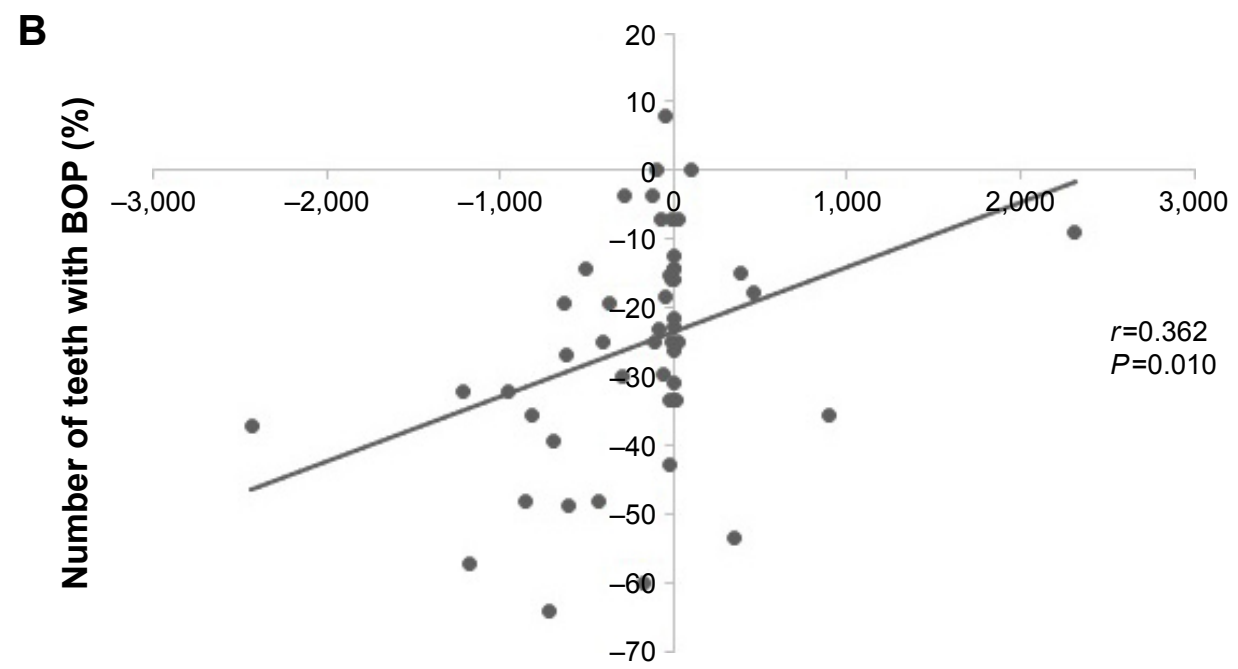

Change in the copy count of $T$. denticola $\left(\times 10^{3}\right.$ copy $/ 5 \mu \mathrm{L}$ saliva)

Figure I Pearson's product-moment correlation coefficient between the change in periodontal tests and the copy count of Treponema denticola. (A) Correlation between the change in the copy count of $T$. denticola and the median percentage of the number of teeth with PPD $\geq 4 \mathrm{~mm}$ (correlation coefficient $r=0.4 \mathrm{I}$, significant difference $P=0.003$ ). (B) Correlation between the change in the copy count of $T$. denticola and the median percentage of teeth with BOP (correlation coefficient $r=0.362$, significant difference $P=0.010$ ).

Abbreviations: BOP, bleeding on probing; PPD, probing pocket depth.

\section{Condition of obesity}

Obesity and metabolic syndrome patients are said to have a chronic inflammatory response throughout the whole body. This is similar to periodontal diseases in that these diseases are all chronic inflammatory diseases. In obese people, adipose tissue has accumulated in subcutaneous and visceral fat. Many macrophages infiltrate and accumulate in adipose tissue, and the secretion of inflammatory cytokines such as tumor necrosis factor-alpha (TNF- $\alpha$ ), interleukin-6 (IL-6), and monocyte chemoattractant protein-1 (MCP-1) increases. ${ }^{23,24}$ TNF- $\alpha$ inhibits the action of insulin receptors and attenuates the insulin signal. It is positively correlated with body fat percentage and blood insulin ${ }^{25,26}$ and tends to exhibit insulin resistance. ${ }^{27}$ IL-6 is a multifunctional cytokine that regulates hematopoiesis, the immune response, and the inflammatory response. It stimulates white adipocytes and inhibits insulin signaling. ${ }^{28} \mathrm{MCP}-1$ is a type of inflammatory cytokine that induces macrophages into white adipocytes. ${ }^{29}$ In periodontitis, these inflammatory cytokines are recognized in significant numbers and have an effect on glucose metabolism and lipid metabolism..$^{30}$ In addition, obese people have decreased ability to produce adiponectin, an anti-inflammatory cytokine ${ }^{25}$ that is resistant to leptin, which enhances insulin sensitivity. ${ }^{31}$ Leptin has been identified as a causative gene for hereditary obesity and is deeply involved in attachment loss in periodontal disease. Leptin concentration in the blood increases as 
Table 5 Correlation between change in the copy count of periodontal disease-causing bacteria and body weight, blood test results

\begin{tabular}{llll}
\hline Variable & \multicolumn{3}{l}{ Exercise intervention group $(\mathbf{n}=\mathbf{5 0})$} \\
\cline { 2 - 4 } & $\begin{array}{l}\text { Porphyromonas } \\
\text { gingivalis }\end{array}$ & $\begin{array}{l}\text { Tannerella } \\
\text { forsythia }\end{array}$ & $\begin{array}{l}\text { Treponema } \\
\text { denticola }\end{array}$ \\
\hline Body weight $(\mathrm{kg})$ & 0.573 & 0.115 & $0.008^{*}$ \\
AST $(\mathrm{U} / \mathrm{L})$ & 0.768 & 0.840 & 0.488 \\
ALT $(\mathrm{U} / \mathrm{L})$ & 0.743 & 0.597 & 0.859 \\
$\gamma-\mathrm{GT}(\mathrm{U} / \mathrm{L})$ & 0.999 & 0.761 & 0.485 \\
T-Cho $(\mathrm{mg} / \mathrm{dL})$ & 0.543 & 0.655 & 0.210 \\
HDL-C $(\mathrm{mg} / \mathrm{dL})$ & 0.644 & 0.372 & 0.556 \\
LDL-C $(\mathrm{mg} / \mathrm{dL})$ & 0.080 & 0.208 & $0.049 *$ \\
FFAs $(\mathrm{mEg} / \mathrm{L})$ & 0.397 & 0.102 & 0.952 \\
Fasting blood & 0.980 & 0.701 & 0.545 \\
glucose $(\mathrm{mg} / \mathrm{dL})$ & & & \\
Fasting insulin $(\mu \mathrm{U} / \mathrm{mL})$ & 0.532 & 0.355 & $0.041^{*}$ \\
HbAlc $(\%)$ & 0.960 & 0.201 & 0.111 \\
\hline Notes & &
\end{tabular}

Notes: All data are for the amount of change from pre- to postintervention. Pearson's product-moment correlation coefficient was used for analysis. $* P<0.05$. Abbreviations: ALT, alanine transaminase; AST, aspartate transaminase alanine; FFAs, free fatty acids; $\gamma$-GT, gamma glutamyl transferase; HbAlc, hemoglobin AIc; HDL-C, high-density lipoprotein cholesterol; LDL-C, low-density lipoprotein cholesterol.

periodontal tissue destruction increases. ${ }^{32}$ Obese people have increased sensitivity to lipopolysaccharide (LPS). ${ }^{33}$ There are many reports suggesting that LPS derived from periodontal disease-causing bacteria affects systemic diseases. One study found a relationship between ischemic heart disease $\mathrm{e}^{34}$ and LPS derived from periodontal disease-causing bacteria, and another study demonstrated a relationship between nonalcoholic fatty liver disease and LPS derived from periodontal disease-causing bacteria. ${ }^{35}$ LPS derived from periodontal disease is likely to result in a deterioration in periodontal disease as LPS sensitivity increases.

\section{Effect of exercise habits}

It has been demonstrated that liver function improves with habitual exercise. ${ }^{16}$ In general, habitual exercise activates local immunocompetent cells such as macrophages, neutrophils, and lymphocytes. ${ }^{36}$ As the function of macrophages is enhanced, dendritic cells are activated in the periphery. Dendritic cells activate and regulate microbial infection with innate immune responses and adaptive immune responses and are involved in immune responses in chronic periodontitis. ${ }^{37,38}$ In a study that divided subjects into a nonexercise group, a long-term moderate exercise group, and a high-intensity exercise group, the peripheral blood neutrophil and lymphocyte concentration were significantly higher in the long-term moderate exercise group than in the other groups, ${ }^{39}$ confirming that moderate exercise is beneficial immunologically.
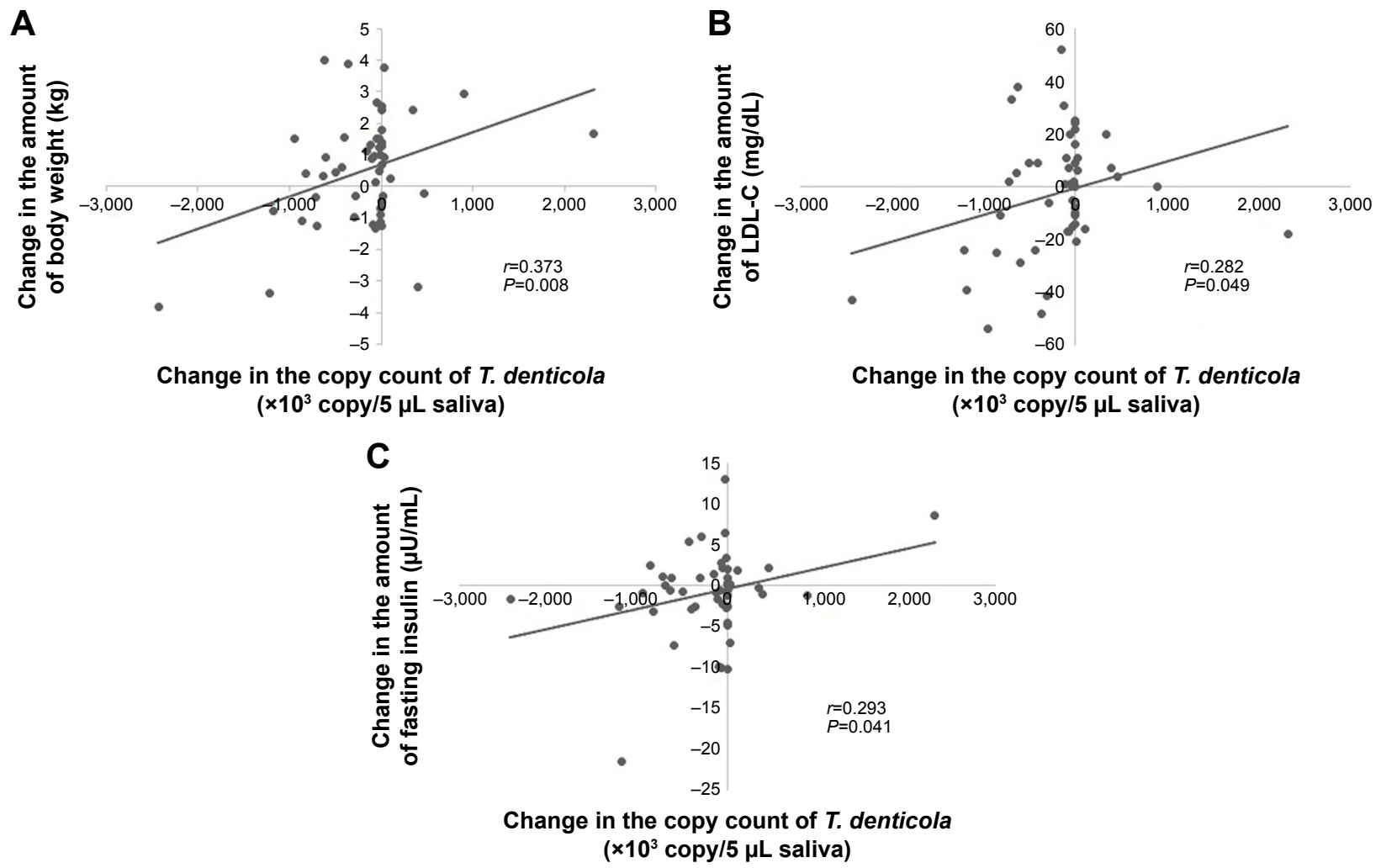

Figure 2 Pearson's product-moment correlation coefficient between the change in body weight and blood tests and the copy count of Treponema denticola. (A) Correlation between the change in the copy count of $T$. denticola and the change in body weight (correlation coefficient $r=0.373$, significant difference $P=0.008$ ). (B) Correlation between the change in the copy count of $T$. denticola and the change in LDL-C (correlation coefficient $r=0.282$, significant difference $P=0.049$ ). (C) Correlation between the change in the copy count of $T$. denticola and the change in fasting insulin (correlation coefficient $r=0.293$, significant difference $P=0.04 \mathrm{I}$ ).

Abbreviation: LDL-C, low-density lipoprotein cholesterol. 
Table 6 Correlation between change in the copy count of periodontal disease-causing bacteria and body weight, blood test results

\begin{tabular}{|c|c|c|c|}
\hline \multirow[t]{2}{*}{ Variable } & \multicolumn{3}{|c|}{ Dietary intervention group $(n=2 I)$} \\
\hline & $\begin{array}{l}\text { Porphyromonas } \\
\text { gingivalis }\end{array}$ & $\begin{array}{l}\text { Tannerella } \\
\text { forsythia }\end{array}$ & $\begin{array}{l}\text { Treponema } \\
\text { denticola }\end{array}$ \\
\hline Body weight (kg) & $0.94 I$ & 0.936 & 0.914 \\
\hline AST (U/L) & 0.539 & 0.335 & 0.972 \\
\hline ALT (U/L) & 0.199 & 0.200 & 0.578 \\
\hline$\gamma-\mathrm{GT}(\mathrm{U} / \mathrm{L})$ & 0.747 & 0.784 & 0.851 \\
\hline T-Cho (mg/dL) & 0.729 & 0.460 & 0.724 \\
\hline HDL-C (mg/dL) & 0.711 & 0.899 & 0.592 \\
\hline LDL-C (mg/dL) & 0.903 & 0.421 & 0.446 \\
\hline FFAs (mEq/L) & 0.078 & 0.807 & 0.807 \\
\hline Ferritin $(\mu g / L)$ & 0.236 & 0.233 & 0.493 \\
\hline $\begin{array}{l}\text { Fasting blood glucose } \\
(\mathrm{mg} / \mathrm{dL})\end{array}$ & 0.863 & 0.978 & 0.911 \\
\hline Fasting insulin $(\mu \mathrm{U} / \mathrm{mL})$ & 0.521 & 0.996 & 0.266 \\
\hline $\mathrm{HbAlc}(\%)$ & 0.856 & 0.935 & 0.922 \\
\hline
\end{tabular}

Notes: All data are for the amount of change from pre- to postintervention. Pearson's product-moment correlation coefficient was used for analysis. Abbreviations: ALT, alanine transaminase; AST, aspartate transaminase alanine; FFAs, free fatty acids; $\gamma$-GT, gamma glutamyl transferase; HbAlc, hemoglobin Alc; HDL-C, high-density lipoprotein cholesterol; LDL-C, low-density lipoprotein cholesterol.

Long-term habitual exercise has been shown to reduce subcutaneous and visceral fat, decrease basal levels of inflammatory cytokines such as TNF- $\alpha$, IL- 6 , and MCP-1, and increase anti-inflammatory cytokines such as adiponectin. ${ }^{28,29,40,41}$ Calorie restriction and walking training were conducted for severely obese men for 3 weeks, and they resulted in a significant decrease in the expression of macrophages in visceral fat, a significant decrease in IL-6 in the blood, and a significant increase in adiponectin. ${ }^{40}$ Another study demonstrated that exercise reduces leptin gene expression in visceral fat and that blood leptin concentration decreases after exercise. ${ }^{31}$ The findings of these studies indicate that exercise habits could reduce local inflammatory cytokines, activate immunocompetent cells, and improve the pathological condition of periodontitis.

\section{Periodontal disease and liver function}

In this study, ALT and $\gamma$-GT decreased significantly before and after the exercise intervention. Several studies have reported that there is a relationship between periodontal disease and liver function. In a study of young adults, it was reported that in 104 (4.7\%) men with periodontitis, there was a significant association with an increased level of ALT ( $\leq 41 \mathrm{IU} / \mathrm{L})$ in logistic regression analysis (adjusted odds ratio $=2.3 ; 95 \%$ confidence interval $=1.0-5.2 ; P<0.05) .{ }^{42}$ In females, the incidence of periodontitis (PPD $\geq 4 \mathrm{~mm}$ ) was significantly higher in those with elevated serum levels of AST $(P<0.01)$, ALT $(P<0.01)$, and cholinesterase $(P<0.001)$ and an AST-toALT ratio of $<1(P=0.02) .{ }^{43}$ In addition, it has been reported that in men with low alcohol consumption, there is a significant association between periodontal pocket depth and the coexistence of elevated ALT and metabolic syndrome. ${ }^{44}$ These findings indicate that periodontal disease is closely related to liver function. Therefore, improving liver function by increasing exercise is likely to improve periodontal disease.

\section{Periodontal disease and hyperlipidemia}

In patients with chronic periodontitis, LDL-C and triglycerides tend to be higher. It is suggested that periodontal disease may be a risk factor for hyperlipidemia. ${ }^{45}$ It has also been reported that moderate exercise habits improve hyperlipidemia and lower HDL-C and LDL-C. ${ }^{46}$ In particular, aerobic exercise is said to be effective for LDL-C reduction. ${ }^{47} \mathrm{In}$ this study, because a positive correlation was found between LDL-C and periodontitis-causing bacteria, the possibility that T. denticola might be involved in the association between hyperlipidemia and periodontal disease was considered.

\section{Periodontal disease and exercise habits}

Recent investigations have demonstrated that inflammatory cytokines (such as TNF- $\alpha$ and IL-6) and blood leptin concentration decreased and adiponectin increased in obese subjects suffering from chronic periodontitis with nonsurgical periodontal disease treatment. ${ }^{48,49}$ This is similar to the effect achieved with an increase in exercise. Thus, habitual exercise may activate the immune system and reduce inflammatory cytokines, resulting in a reduction in obesity and lifestylerelated diseases. One study reported that the prevalence of upper respiratory tract infections is significantly decreased in subjects who habitually exercise.$^{50}$ It is possible that the establishment of appropriate exercise habits improves periodontal disease through the activation of the immune system and a reduction in inflammatory cytokines, and it is presumed that this effect is similar to that of nonsurgical periodontal treatment on obese people. A recent clinical study proposed that obesity should be controlled before or during periodontal disease treatment. ${ }^{51}$ The available research suggests that exercise habits may have a synergistic effect in the improvement of periodontal disease with the usual periodontal treatment.

\section{Limitations}

One limitation of our study is that we did not evaluate inflammatory cytokines. Further trials evaluating the local immune 
response and further basic research about $T$. denticola are needed to confirm our findings. Furthermore, this study investigated only male subjects. The prevalence of periodontal disease is thought to be higher in males than in females, but it has not been clarified whether this sex difference is a result of the effect of exercise habits. According to our findings, the tendency for obesity was also reduced in the dietary intervention group. In this study, because there was no association between periodontal disease-causing bacteria and the dietary intervention group, the improvement in periodontal disease may be caused by factors that are specific to habitual exercise.

Our results showed for the first time that habitual exercise may contribute to improvement in periodontal disease. We propose that future treatment options for periodontal disease should include encouragement to establish regular exercise habits.

\section{Conclusion}

Our findings suggest that habitual exercise may contribute not only to improvement in periodontal disease but also to improvement in the pathology of lifestyle-related diseases.

\section{Acknowledgments}

We would like to thank Mr Takashi Shida and Dr Takehito Terabe for analysis and interpretation of data and Dr Kenji Yamagata and Naomi Ishibasi-Kanno for advice and guidance. This work was supported in part by Grants-in-Aid for Scientific Research from the Ministry of Education, Culture, Sports, Science and Technology, Japan (numbers 26293284 , 15K15037, 16H03255, 15H04917, and 17H02174).

\section{Disclosure}

The authors report no conflicts of interest in this work.

\section{References}

1. Linden GJ, Herzberg MC; Working Group 4 of Joint EFP/AAP Workshop. Periodontitis and systemic diseases: a record of discussions of working group 4 of the Joint EFP/AAP Workshop on Periodontitis and Systemic Diseases. J Clin Periodontol. 2013;40(Suppl 14):S20-S23.

2. Socransky SS, Haffajee AD, Cugini MA, Smith C, Kent RL Jr. Microbial complexes in subgingival plaque. J Clin Periodontol. 1998; 25(2):134-144

3. Yoneda M, Naka S, Nakano K, et al. Involvement of a periodontal pathogen, Porphyromonas gingivalis on the pathogenesis of non-alcoholic fatty liver disease. BMC Gastroenterol. 2012;12:16.

4. Grundy SM. Metabolic syndrome scientific statement by the American Heart Association and the National Heart, Lung, and Blood Institute. Arterioscler Thromb Vasc Biol. 2005;25(11):2243-2244.

5. Nishimura F, Murayama Y. Periodontal inflammation and insulin resistance - lessons from obesity. J Dent Res. 2001;80(8):1690-1694.
6. Al-Zahrani MS, Bissada NF, Borawskit EA. Obesity and periodontal disease in young, middle-aged, and older adults. J Periodontol. 2003; 74(5):610-615.

7. Socransky SS, Haffajee AD. Periodontal microbial ecology. Periodontol 2000. 2005;38:135-187.

8. D'Aiuto F, Sabbah W, Netuveli G, et al. Association of the metabolic syndrome with severe periodontitis in large U.S. population-based survey. J Clin Endocrinol Metab. 2008;93(10):3989-3994.

9. Morita T, Yamazaki Y, Mita A, et al. A cohort study on the association between periodontal disease and the development of metabolic syndrome. J Periodontol. 2010;81(4):512-519.

10. Chaffee BW, Weston SJ. Association between chronic periodontal disease and obesity: a systematic review and meta-analysis. J Periodontol. 2010;81(12):1708-1724.

11. Suvan J, D'Aiuto F, Moles DR, Petrie A, Donos N. Association between overweight/obesity and periodontitis in adults. A systematic review. Obes Rev. 2011;12(5):e381-e404.

12. Gleeson M. Immune function in sport and exercise. J Appl Physiol (1985). 2007;103(2):693-699.

13. Booth FW, Chakravarthy MV, Gordon SE, Spangenburg EE. Waging war on physical inactivity: using modern molecular ammunition against an ancient enemy. $J$ Appl Physiol (1985). 2002;93(1):3-30.

14. Al-Zahrani MS, Borawski EA, Bissada NF. Increased physical activity reduces prevalence of periodontitis. J Dent. 2005;33(9):703-710.

15. Oh S, So R, Shida T, et al. High-intensity aerobic exercise improves both hepatic fat content and stiffness in sedentary obese men with nonalcoholic fatty liver disease. Sci Rep. 2017;7:43029.

16. Oh S, Tanaka K, Warabi E, Shoda J. Exercise reduces inflammation and oxidative stress in obesity-related liver diseases. Med Sci Sports Exerc. 2013;45(12):2214-2222.

17. Grbic JT, Lamster IB, Celenti RS, Fine JB. Risk indicators for future clinical attachment loss in adult periodontitis. Patient variables. J Periodontol. 1991;62(5):322-329.

18. Katz PP, Wirthlin MR Jr, Szpunar SM, Selby JV, Sepe SJ, Showstack JA. Epidemiology and prevention of periodontal disease in individuals with diabetes. Diabetes Care. 1991;14(5):375-385.

19. Haber J, Wattles J, Crowley M, Mandell R, Joshipura K, Kent RL. Evidence for cigarette smoking as a major risk factor for periodontitis. J Periodontol. 1993;64(1):16-23.

20. Shizukuishi S, Hayashi N, Tamagawa H, et al. Lifestyle and periodontal health status of Japanese factory workers. Ann Periodontol. 1998;3(1): 303-311.

21. Marcenes WS, Sheiham A. The relationship between work stress and oral health status. Soc Sci Med. 1992;35(12):1511-1520.

22. Genco RJ, Ho AW, Kopman J, Grossi SG, Dunford RG, Tedesco LA. Models to evaluate the role of stress in periodontal disease. Ann Periodontol. 1998;3(1):288-302.

23. Yamashita A, Soga Y, Iwamoto Y, et al. Macrophage-adipocyte interaction: marked interleukin-6 production by lipopolysaccharide. Obesity (Silver Spring). 2007;15(11):2549-2552.

24. Wellen KE, Hotamisligil GS. Inflammation, stress, and diabetes. J Clin Invest. 2005;115(5):1111-1119.

25. Tilg H, Moschen AR. Adipocytokines: mediators linking adipose tissue, inflammation and immunity. Nat Rev Immunol. 2006;6(10):772-783.

26. Cawthorn WP, Sethi JK. TNF-alpha and adipocyte biology. FEBS Lett. 2008;582(1):117-131.

27. Hotamisligil GS. Inflammation and metabolic disorders. Nature. 2006; 444(7121):860-867.

28. Petersen AM, Pedersen BK. The anti-inflammatory effect of exercise. J Appl Physiol (1985). 2005;98(4):1154-1162.

29. Sakurai T, Izawa T, Kizaki T, et al. Exercise training decreases expression of inflammation-related adipokines through reduction of oxidative stress in rat white adipose tissue. Biochem Biophys Res Commun. 2009; 379(2):605-609.

30. Grossi SG, Genco RJ. Periodontal disease and diabetes mellitus: a two-way relationship. Ann Periodontol. 1998;3(1):51-61. 
31. Berggren JR, Hulver MW, Houmard JA. Fat as an endocrine organ: influence of exercise. J Appl Physiol (1985). 2005;99(2):757-764.

32. Zimmermann GS, Bastos MF, Dias Gonçalves TE, Chambrone L, Duarte PM. Local and circulating levels of adipocytokines in obese and normal weight individuals with chronic periodontitis. $J$ Periodontol. 2013;84(5):624-633.

33. Yang SQ, Lin HZ, Lane MD, Clemens M, Diehl AM. Obesity increases sensitivity to endotoxin liver injury: implications for the pathogenesis of steatohepatitis. Proc Natl Acad Sci U S A. 1997;94(6):2557-2562.

34. Beck JD, Offenbacher S, Williams R, Gibbs P, Garcia R. Periodontitis: a risk factor for coronary heart disease? Ann Periodontol. 1998;3(1): $127-141$.

35. Furusho H, Miyauchi M, Hyogo H, et al. Dental infection of Porphyromonas gingivalis exacerbates high fat diet-induced steatohepatitis in mice. J Gastroenterol. 2013;48(11):1259-1270.

36. Murphy EA, Davis JM, Brown AS, et al. Role of lung macrophages on susceptibility to respiratory infection following short-term moderate exercise training. Am J Physiol Regul Integr Comp Physiol. 2004; 287(6):R1354-R1358.

37. Ho CS, López JA, Vuckovic S, Pyke CM, Hockey RL, Hart DN. Surgical and physical stress increases circulating blood dendritic cell counts independently of monocyte counts. Blood. 2001;98(1):140-145.

38. Nakajima T, Amanuma R, Ueki-Maruyama K, et al. CXCL13 expression and follicular dendritic cells in relation to B-cell infiltration in periodontal disease tissues. J Periodontal Res. 2008;43(6):635-641.

39. Saygin O, Karacabey K, Ozmerdivenli R, Zorba E, Ilhan F, Bulut V. Effect of chronic exercise on immunoglobulin, complement and leukocyte types in volleyball players and athletes. Neuro Endocrinol Lett. 2006;27(1-2):271-276.

40. Bruun JM, Helge JW, Richelsen B, Stallknecht B. Diet and exercise reduce low-grade inflammation and macrophage infiltration in adipose tissue but not in skeletal muscle in severely obese subjects. Am J Physiol Endocrinol Metab. 2006;290(5):E961-E967.

41. Trøseid M, Lappegård KT, Claudi T, et al. Exercise reduces plasma levels of the chemokines MCP-1 and IL- 8 in subjects with the metabolic syndrome. Eur Heart J. 2004;25(4):349-355.
42. Furuta M, Ekuni D, Yamamoto T, et al. Relationship between periodontitis and hepatic abnormalities in young adults. Acta Odontol Scand. 2010;68(1):27-33.

43. Saito T, Shimazaki Y, Koga T, Tsuzuki M, Ohshima A. Relationship between periodontitis and hepatic condition in Japanese women. $J$ Int Acad Periodontol. 2006;8(3):89-95.

44. Ahmad A, Furuta M, Shinagawa T, et al. Association of periodontal status with liver abnormalities and metabolic syndrome. J Oral Sci. 2015;57(4):335-343.

45. Nagpal R, Yamashiro Y, Izumi Y. The two-way association of periodontal infection with systemic disorders: an overview. Mediators Inflamm. 2015;2015:793898.

46. Després JP, Lamarche B. Low-intensity endurance exercise training, plasma lipoproteins and the risk of coronary heart disease. $J$ Intern Med. 1994;236(1):7-22.

47. Kelley GA, Kelley KS. Effects of aerobic exercise on lipids and lipoproteins in adults with type 2 diabetes: a meta-analysis of randomizedcontrolled trials. Public Health. 2007;121(9):643-655.

48. Papageorgiou SN, Reichert C, Jäger A, Deschner J. Effect of overweight/obesity on response to periodontal treatment: systematic review and a meta-analysis. J Clin Periodontol. 2015;42(3):247-261.

49. Acharya A, Bhavsar N, Jadav B, Parikh H. Cardioprotective effect of periodontal therapy in metabolic syndrome: a pilot study in Indian subjects. Metab Syndr Relat Disord. 2010;8(4):335-341.

50. Matthews CE, Ockene IS, Freedson PS, Rosal MC, Merriam PA, Hebert JR. Moderate to vigorous physical activity and risk of upper-respiratory tract infection. Med Sci Sports Exerc. 2002;34(8):1242-1248.

51. Akram Z, Safii SH, Vaithilingam RD, Baharuddin NA, Javed F, Vohra F. Efficacy of non-surgical periodontal therapy in the management of chronic periodontitis among obese and non-obese patients: a systematic review and meta-analysis. Clin Oral Investig. 2016;20(5):903-914.
Therapeutics and Clinical Risk Management

\section{Publish your work in this journal}

Therapeutics and Clinical Risk Management is an international, peerreviewed journal of clinical therapeutics and risk management, focusing on concise rapid reporting of clinical studies in all therapeutic areas, outcomes, safety, and programs for the effective, safe, and sustained use of medicines. This journal is indexed on PubMed Central, CAS,

\section{Dovepress}

EMBase, Scopus and the Elsevier Bibliographic databases. The manuscript management system is completely online and includes a very quick and fair peer-review system, which is all easy to use. Visit http://www.dovepress.com/testimonials.php to read real quotes from published authors. 